attributed to the sting of a wasp or other insect, possibly occurring while taking tea, at which the patient ate some strawberry jam. The patient, however, disclaimed any knowledge of having been stung or bitten. There had been no exposure to cold or wet. The bad prognosis given was based upon the afrebile course of the illness, the extremely rapid pulse, the cyanosis and cold sweats with rapid exhaustion. The case was apparently one of septic infection resulting from some cause unknown, unless the hypothetical sting be looked upon as the point of entrance of some infective organism. Inquiry was made as to the possibility of infection from any diseased animals or farm stock with a negative result.

Royston, Herts.

\section{INDUCTION OF LABOUR $V$. MORPHINE IN ECLAMPSIA.}

By W. BoXer MAYNe, M.R.C.S. ENG., L.R.C.P. LoNd.

THE following is a report on a severe case of eclampsia showing the relative value of hypodermic injections of morphine and induction of labour as treatment.

I was called about 7 A.M. to see a young woman whose husband informed me that she was eight months pregnant and that she had just had a fit. On arrival at the house I found that the patient, a primipara, 20 years of age, had had in the meantime a second fit, the first having occurred about 6 A.M. and the second about 7 A.M. On inquiry I found further that she had complained for a day or two of violent headache and also of pains in the back. She was very puffed about the face, her feet and ankles being very cdematous. Though strange and excitable in her manner she nevertheless allowed, after a little persuasion, a vaginal examination; the os was of about the size of a shilling and the vertex was presenting. Having found morphine a great success in other cases I resolved to give the same treatment further trial and, as before, to commence with a hypodermic injection of half a grain. Whilst getting the injection ready the patient had a third severe fit. In addition to the morphine I placed two minims of croton oil with a little butter on her tongue and had her wrapped in a hot pack. At 10 A.M. she had a fourth fit, a nurse in attendance administering, by my instruction, a further hypodermic injection of a quarter of a grain of morphine, which was repeated by myself about 12.30 A.M., the patient being then in a semi-conscious state. I had no sooner gone than the patient had a fifth fit; and at 3 P.M. a sixth, when the nurse gave her a third hypodermic injection of a quarter of a grain of morphine. Seeing the patient again at 4.30 and finding that she had had the two fits since my previous visit and that she was in a comatose condition, $I$ determined to postpone no longer the last resource, viz., induction of labour. $\Delta d$. ministering chloroform, I managed to dilate the os sufficiently to enable me to perform version; accelerating matters by traction I presently delivered a living child. As a precaution I gave a hypodermic injection of four tabloids of ergotinine citrate, each 1-200th grain, and one of strychnine, 1-30th grain. From this time nothing untoward occurred; the patient spent a quiet night and was able to recognise me the following morning, though still dazed and heary. During the day she passed a little urine with her motions, and the day following, under the influence of diuretics, \&c., a fair amount; this, the first I had been able to examine, presented about one-third albumin. The progress of the patient since has been uninterrupted.

Swindon.

A CASE OF PLASTIC RESECTION OF THE BREAST AND ITS BEARING ON THE ROUTINE PRELIMINARY INCISION OF BREAST TUMOURS.

By C. Hamilton Whiteford, M.R.C.S. EnG., L.R.C.P. LOND.

THE patient, aged 24 years, married, one child 19 months old, was operated upon on Nov. 10th, 1907, and was shown at a meeting of the Plymouth Medical Society on Feb. 19th last. For the past four months she had noticed in the centre of the upper and inner quadrant of the left breast a tender thickened area of the size of half-a-crown. 'This tender area, after treatment by local applications for four months, was still a source of discomfort to the patient who, having to be anæsthetised for operation on an anal fistula, decided to have the breast dealt with at the same time. The breast was treated by Collins-Warren's modification of Thomas's operation. The skin incision, nine inches in length, exposing the fibres of the greater pectoral muscle, commenced in the nipple line in the fold below the breast, was prolonged upwards along the lower and outer margin of the breast and was further extended along the under surface of the anterior axillary fold. The breast was then dissected upwards and inwards off the greater pectoral muscle until the deep surface of the upper and inner quadrant was exposed. The mass was incised on its deep surface and the diagnosis of chronic mastitis was confirmed. The segment of breast tissue containing the tumour was excised. This wedge-shaped area included the whole thickness of the breast, but stopped short at the subcutaneous fat, which was not disturbed. The base of the wedge measured three inches; the apex of the wedge was situated one inch above and one inch to the inner side of the nipple. The breast was reconstructed by closing the wedge-shaped gap and fixed in its normal position. This was done by four layers of catgut sutures. The first layer, including the subcutaneous fat, approximated the superficial portions of divided breast tissue. The second layer approximated the deep portions of cut breast surface. The third layer, the breast having been turned down into its natural position, attached the breast to the edge of the greater pectoral muscle. The fourth layer approximated the connective tissine immediately beneath the skin incision, which was sutured as advised by Warren without drainage. In spite of many ligatures and firm pressure by dressings a hæmatoma developed between the breast and the greater pectoral muscle. This hæmatoma became infected and was drained through the skin incision.

When seen four months after the operation the breast was in its natural position, the skin over the resected area was normal, showed no depression, with only a suspicion of flattening, and admitted of the wearing of a low evening dress. It is interesting to note that this satisfactory result ensued in spite of the unfortunate incident of the hæmatoma. The long skin incision and freeing of the breast by cutting off the nerve-supply rendered the lower portion of the breast at first almost completely anæsthetic. At the present time this anæsthesia has nearly disappeared. In view of the extensive area involved in the dissection it is probably safer to drain for 24 hours the retro-mammary tissues by a tube passed from the lowest part of the skin incision to the deep surface of the sutured breast area.

The above method has an important bearing on the best position for the preliminary incision, which should be made into every breast tumour as a preliminary to radical treatment. The surgeon who, in performing a radical operation for supposed malignant disease of the breast, neglects the elementary precaution of incising the tumour, as a means of either confirming or disproving the diagnosis, runs the risk of finding himself in the unenviable position of having performed Halsted's, or some equally extensive operation, for a simple tumour such as an adenoma or abscess. An incision made into the tumour directly through the overlying skin in the event of the tumour proving non-malignant and needing only local removal, results to a certainty in a scar and probably in a depression. This scar, or scar plus depression, if situated in the upper half of the breast, interferes with the wearing of a low-necked dress. By employing Warren's skin incision, followed by incision of the tumour on its deep surface, such disfigurement can be avoided. If the tumour is found to be innocent it can be treated as in the case recorded above. If the tumour proves to be malignant, in order to minimise risk of dissemination of cancer cells its cut surface is cauterised and a pad of gauze is packed between the breast and the greater pectoral muscle. The breast is turned outwards and downwards so as to occupy its normal position and is fixed to the greater pectoral muscle by a continuous suture. After discarding all instruments, gloves, \&c., used for the exploratory incision, a fresh supply is employed in the performance of the radical operation.

Adoption of the above method (which, while not unknown, is certainly not in general use) as a routine preliminary to 
operations on mammary tumours situated in the upper half of the breast will, in the case of an innocent tumour, prevent a disfigurement which, to a sensitive patient, is distressing and surgically is unnecessary.

Plymouth.

\section{altlovital Sortictirs.}

\section{ROYAL SOCIETY OF MEDICINE.}

\section{OBSTETRICAL AND GYNACOLOGICAL SECTION. \\ Ovaman Pregnancy Co-existing nith Intra-uterine Preg. nanoy.-Exhibition of Specimen.}

A / MEETING of this section was held on June.11th, Dr. HERBERT R. SPENCER, the President, being in the chair.

Dr. J. M. MunRo KeRR read a paper on a case of Ovarian Pregnancy Co-existing with Intra-uterine Pregnancy. The ovary containing the ovarian pregnancy was removed by operation. The embryo was at a stage closely corresponding to one described by Graf von Spee. It was so much injured, however, that reconstruction was not possible and the sections were exhibited, the ovum being the youngest yet recorded in that position, to demonstrate the nature of imbedding in the ovary. There was a large corpus luteum, the contour of which was intact, except at one point where there was young organising connective tissue, forming a continuous strand reaching from the centre of the corpus luteum to the margin of the implantation cavity. The cavity had been excavated in the ovarian stroma, and its walls were formed in part of connective tissue in a state of coagulation necrosis, but to a greater extent by fibrin and blood clot. The surface of the ovary had been ruptured and the ovum was evidently in the process of extrusion. There were absolutely no signs of any formation akin to decidua and the more actively destructive phases demonstrated in the first specimen had obviously persisted until a considerable part of the ovary had been destroyed. The ovum lay more or less free in the implantation cavity; the villi were irregular and many were overtaken by degenerative changes but they contained blood-vessels and showed precisely the same coverings as in a uterine ovum at the same stage of development. The sections prove: 1 . That the orum can be imbedded in the ovarian stroma outside the Graafian follicle. 2. That it imbeds itself just as does the ovum in the uterus in connective tissue rich in blood-vessels. 3. As has already been shown by $\mathrm{C}$. von Tussenbroeck and others, the uterine epithelium is not necessary for plasmodial formation; as this ovum lies in the ovarian stroma neither can the plasmodium be derived from the follicular epithelium. The two cases combined once again demonstrate the nature of implantation. The process involved is essentially a destructive one; the primary necessity for the orum is a nidus of connective tissue rich in blood-ressels. Formation of decidua is not essential; it is a defensive reaction against the destructive activities of the trophoblast, which it limits and controls.

Dr. JOHN H. TEACHER gave lantern and microscopic demonstration of an extremely young human ovum (TeacherBryce orum). This specimen represents the earliest stage of the human ovum which has been found and presents features hitherto unknown. The ovum was found by Dr. Teacher in a portion of decidua shed by abortion. It is imbedded in the decidua in an oval cavity filled with maternal blood and having a small orifice closed by a fibrinous plug. The walls of the blastocyst (which measures internally $0.77 \mathrm{by}$ 0.63 by 0.50 millimetre) are composed of a thin cellular layer and a very irregular plasmodial formation together constituting the trophoblast. Within this there is a delicate mesoderm, towards the centre of which lies an extremely small embryonic rudiment. The ovum, although imbedded, is not yet attached to the decidua. An unusually clear history has been obtained, which appears to afford a fresh starting point for the estimation of the age of young ova in general. The age of the present ovum is estimated at from 13 to 14 days from fertilisation.

\section{THERAPEUTICAL AND PHARMACOLOGICAL SECTION.} Demonstration of Experiments.

A MEETING of this section was held on June 27th, on the invitation of Professor A. R. Cushny, in the Pharmacological
Laboratory of University College, London, Dr. T. E. BuntoN Brown, the President, being in the chair.

Professor CUsHNy showed some most interesting experiments demonstrating graphically the effect produced on a dog's heart (the animal being in a condition of complete anæsthesia) by the administration of certain drugs such as chloroform, when the heart's action weakened, ether, and pilocarpine.

The museum of the College was visited and the valuable exhibition of Egyptian antiquities collected by Professor Flinders Petrie was viewed.

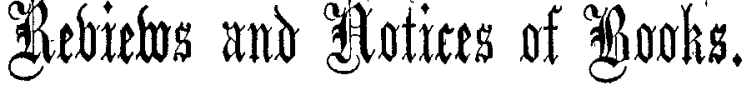

Gynecology and Abdominal Surgery. Edited by HowARD A. KELlY, M.D., F.R.C.S. Edin. (Hon.), Professor of Gynæcologic Surgery at the Johns Hopkins University; and Charles P. Noble, M.D., Clinical Professor of Gynæcology at the Women's Medical College, Philadelphia. Illustrated by HeRM AN BECKER, MAX BRöDEL, and others. London and Philadelphia: W. B. Saunders Company. 1907. Vol. I. Pp. 851.

IN the preface to this work the editors point out that the great advances made in gynæcology have constituted the very backbone of the abdominal surgery of to-day, and that pari passu with the labours of the gynæcologists have gone the developments of the abdominal surgery of the abdomen as a whole. That the operating gynæcologist should have had a thorough training in general surgery is an essential which is liable to be overlooked by some writers, and the likelihood of an abdominal operation, even when undertaken apparently for the simplest gynæcological affection, calling for the exercise of the highest skill of the general surgeon is no small one. The present work, therefore, seems to us to be of value in the stress which it lays on the close relationship between general abdominal surgery and gynæcology.

The first chapter on gynæcological technique is written by Professor Howard Kelly and contains a complete account of the various methods of sterilisation. The scientific basis of gynæcology is set forth in two chapters concerned with the bacteriology and pathology of the diseases of women. This arrangement leads to a certain amount of repetition, but as regards the pathological anatomy of the various affections this is more than compensated for by the excellence of the chapter on pathology which is contributed by Dr. Elizabeth Hurdon.

In the chapter devoted to medical gynæcology, by Dr. Charles P. Noble and Dr. Brooke M. Anspach, such conditions as disorders of menstruation, inflammatory affections and infections of the pelvic organs, and displacements of the uterus are considered, as well as the various neuroses which may be met with in gynæcological patients.

The next chapter is headed Non-plastic Operations on the Vulva and Vagina, and is written by Dr. Anna M. Fullerton. In this are included such different processes as inflammatory diseases, ulcerative processes, hypertrophy, and atrophy of tissues and new growths. The important subjects of plastic operations on the perineum, vagina, and vulva are fully discussed in the next chapter by Dr. Noble who deals with them at considerable length. He prefers Emmet's operation in the treatment of cases of relaxed vaginal outlet and thinks that it is better than 'Tait's flapsplitting operation, because the latter does not afford any satisfactory means of disposing of a rectocele and of securing union of the torn or separated fibres of the levator ani muscle. In the treatment of cases of chronic inversion of the uterus discission of the cervix, followed if necessary by incision of the body of the uterus from below upwards, is preferred to Küstner's operation.

The section on the diseases of the bladder and urethra, by 